\title{
Article \\ Preliminary Study on Citrus Oils Antibacterial Activity Measured by Flow Cytometry: A Step-by-Step Development
}

\author{
Nayeli G. Nieto-Velázquez ${ }^{1,+}+\mathbb{D}$, Alejandra A. Gomez-Valdez ${ }^{2,+}{ }^{\dagger}$ Marisela González-Ávila ${ }^{3}$, \\ Jaime Sánchez-Navarrete ${ }^{4}$, Julia D. Toscano-Garibay ${ }^{1, *}$ and Nancy J. Ruiz-Pérez ${ }^{1, *}$ \\ 1 Dirección de Investigación y Enseñanza, Hospital Juárez de México, Ciudad de México 07760, Mexico; \\ goretinieto@gmail.com \\ 2 Facultad de Estudios Superiores Cuatitlán, Universidad Nacional Autónoma de México, \\ Cuautitlán Izcalli 54740, Mexico; alejandraanaid.gomezvaldez30@gmail.com \\ 3 Centro de Investigación y Asistencia en Tecnología y Diseño del Estado de Jalisco (CIATEJ), \\ Guadalajara 44270, Mexico; mgavila@ciatej.mx \\ 4 Unidad de Banco de Sangre, Hospital Juárez de México, Ciudad de México 07760, Mexico; \\ meyula@hotmail.com \\ * Correspondence: julia.toscano@gmail.com (J.D.T.-G.); abril_cics@yahoo.com.mx (N.J.R.-P.); \\ Tel.: +52-55-3894-8337(J.D.T.-G.); +52-55-2575-3187 (N.J.R.-P.) \\ + These authors contributed equally to this work.
}

\section{check for} updates

Citation: Nieto-Velázquez, N.G.; Gomez-Valdez, A.A.; González-Ávila, M.; Sánchez-Navarrete, J.; Toscano-Garibay, J.D.; Ruiz-Pérez, N.J. Preliminary Study on Citrus Oils Antibacterial Activity Measured by Flow Cytometry: A Step-by-Step Development. Antibiotics 2021, 10, 1218. https://doi.org/10.3390/ antibiotics 10101218

Academic Editor: William N. Setzer

Received: 24 August 2021

Accepted: 1 October 2021

Published: 7 October 2021

Publisher's Note: MDPI stays neutral with regard to jurisdictional claims in published maps and institutional affiliations.

Copyright: (c) 2021 by the authors. Licensee MDPI, Basel, Switzerland. This article is an open access article distributed under the terms and conditions of the Creative Commons Attribution (CC BY) license (https:/ / creativecommons.org/licenses/by/ $4.0 /)$.

\begin{abstract}
Essential oils of Citrus sinensis and Citrus latifolia have shown biological functions as antiseptics, anti-inflammatories, antioxidants, antifungal and antimutagenic, so the evaluation of their antibacterial capacity, by themselves or in combination with standard antibiotics, presents an alternative for infection treatment. Flow cytometry opens the door for the design of faster and more accurate measurement of antibacterial activity. We use a SYTO9/PI staining system on E. coli ATCC 25922 to determine antibacterial activity by counting live and dead cells through flow cytometry. We found that dual staining showed highly variable results due to wavelength overlapping and instead we used fluorochrome individual staining that highly correlated with viable counts. Chloramphenicol and cefotaxime treatments did not present a dose-response behavior, rendered diffuse readings and/or gave filament formation on fluorescence microscopy. Amikacin was a better comparison standard because it presented a dose-response behavior. Essential oils had low antibacterial activity as compared to amikacin, with a maximum of $10 \%$ and $20 \%$ for C. latifolia and $C$. sinensis, respectively. Combinations of essential oils with antibiotic resulted in an unforeseen strong inhibition of amikacin activity. Although a low antibacterial activity was found, a series of standardization steps are proposed for antibacterial activity measurement by flow cytometry.
\end{abstract}

Keywords: resistance; E. coli; flow cytometry; essential oils; citrus; viability

\section{Introduction}

The World Health Organization has identified antibacterial resistance as one of the most dangerous threats to human health worldwide. The increasing number of resistant pathogens has compromised the efficacy of antibiotic stewardship and rates of associated morbimortality and economic burden have become seriously elevated in recent times [1]. This phenomenon has motivated the development of new antibacterial alternatives for both prophylactic and therapeutic purposes and particularly the research of those with a natural origin. Essential oils (EOs), by their chemical components, are presently considered as promising candidates to this end [2].

EOs are volatile oils produced by means of secondary metabolism of plants, mostly obtained by steam distillation or cold-pressing as opposed to plant extracts which are generated through the use of solvents like acetone, ethanol and/or hexane [3].

EOs are fragrant and rather transparent substances, while some are colorless when freshly distilled, yellowish when oxidized or colorful when obtained from flowers or 
other colored organs, ranging from pale yellow to green, and from blue to brownish red. EOs are highly soluble in lipids and organic compounds and are generally liquid at room temperature, although some could be solid or resinous $[4,5]$. They are a mixture of monoterpenes, sesquiterpenes, oxygenated derivatives, low weight alkanes, alcohols, aldehydes, ketones, esters and acids, associated with non-volatile paraffins and waxes [6]. EOs are present in all plant organs, including buds, flowers, leaves, seeds, stems, fruits, roots, wood and bark, although there is a general purveyance within secretory cells, cavities, channels and cells of the epidermis [7].

These oils are also known to have antiseptic activities as bactericidal, virucidal and fungicidal agents; medicinal properties as anti-inflammatory, sedative, neuroprotective, neuromodulator and spasmolytic bioactives, and even as antimutagenic and antioxidant $[4,8]$.

It has also been reported that EOs have a wide range of inhibition against a large number of Gram-negative and Gram-positive bacteria. Their lipophilic nature makes them easily penetrative of bacterial cells, and therefore it has been observed that its mechanism of action is based on their ability to alter cell walls and the cytoplasmic membrane. This ability leads to lysis and loss of intracellular components, especially of ions [9], as well as generating a reduction in membrane potential, an interruption of proton pump and a depletion of ATP, among other consequences. It has also been established that the EO antibacterial effect may depend on a series of biochemical reactions typical of bacteria, which are associated with the proportion and type of oil constituents [10].

Also, EOs may produce an inhibitory effect by other mechanisms. It has been shown that its combination with other drugs generates an exceeding effect in comparison to their individual performance, generating greater antibacterial activity. This synergistic activity has been studied in order to reduce the antibiotic dose used for infection treatment. Some accepted theories to explain this phenomenon include the sequential inhibition of common bacterial biochemical pathways, inhibition of protective enzymes and its role as active cell wall agents to improve the diffusion of other antibacterial molecules [5].

On the other hand, Citrus genus is one of the most important crops in terms of world production, according to the Food and Agriculture Organization (FAO) of the United Nations [11]. It belongs to the Rutaceae family, which comprises around 140 genera and 1300 species. The best-known species are C. aurantifolia (lime), C. hystrix (kafir lime), C. limonia (mandarin lime), C. limon (lemon), C. jambhiri (hard lemon), C. sinensis (sweet orange), C. aurantium (bitter orange), C. limetta (sweet lime), C. macroptera (wild orange), C. tachibana (tachibana orange), C. medica (citron), C. nobilis (tangor), C. paradise (grapefruit), C. reticulata (mandarin) and C. tangelo (tangelo) [12]. This genus has played a very important role for centuries and has been used as additive in pharmaceutical, cosmetic and food industries. Citrus species contain abundant amounts of vitamin $\mathrm{C}$ and macronutrients including sugar, dietary fiber, potassium, folate, calcium, thiamine, niacin, vitamin B6, magnesium, riboflavin, and pantothenic acid. Additionally, there are a series of secondary metabolites, such as flavonoids, alkaloids, coumarins, limonoids, carotenoids, phenolic acids and essential oils that are mainly found within the multiple oil chambers on the peel of these fruits, conferring unique aromatic fragrances differentiative from each species and variety. Due to its composition, Citrus genus presents diverse important bioactivities for human health such as antioxidant, anti-inflammatory, cardiovascular protective effect, neuroprotective effect, etc. [13].

One of the most important species among this genus is C. latifolia, commonly known as Persian lemon, which has been used since ancient times for its antiseptic, carminative, diuretic and eupeptic effects [10]. Some of its components, such as $\beta$-caryophyllene, Dlimonene and linalool, have shown anti-inflammatory effects; meanwhile $\alpha$-pinene and $\beta$-pinene inhibit nitric oxide synthesis, suggesting an anti-oxidant role [14]. A recent study showed that $\beta$-pinene also exerts an antispasmodic effect in rat ileum and causes antinociception and that D-limonene have effects as antiulcerogenic, gastroprotective, 
chemoprotective, antiproliferative, insecticidal, antimicrobial, immunomodulatory and reduces symptoms of anxiety when use in aroma-therapy [10,14].

The juice of another member of this genus, $C$. sinensis or sweet orange, is the most consumed fruit juice worldwide for being an excellent source of vitamin $C$ and for its properties as a natural antioxidant that strengthens the immune system [5]. It has been traditionally used to treat constipation, cramps, colic, diarrhea, cough, hypertension, anxiety, depression and stress [15]. Singh et al. [16] revealed the main components of two kinds of orange essential oil as D-limonene, follow by E-citral, Z-citral and carveol, which are recognized as natural antioxidants and food preservatives.

Ruiz et al. [17] demonstrated that the essential oils of C. latifolia and C. sinesis have good antifungal activity against different Candida species. C. latifolia EO was mainly composed of $\mathrm{R}-(+)$-limonene $(51.64 \%), \beta$-thujene $(14.85 \%)$ and $\gamma$-terpinene $(12.8 \%)$, while $C$. sinensis EO was composed primordially R-(+)-limonene $(96 \%)$ and $\alpha$-myrcene $(2.79 \%)$. Both oils were not genotoxic, that is, they do not produce mutations neither by reading frame displacement, base pair substitution, nor by ROS damage when evaluated through Ames test. Furthermore, $C$. sinensis EO did not show a cytotoxic effect on human buccal epithelium cells at doses used for the evaluation of its antifungal activity. However, the EO of C. latifolia was cytotoxic at its highest dose (21.8 $\mu \mathrm{g})$. Additionally, Toscano et al. [18] demonstrated that these same oils have an antimutagenic effect against alkylating, polycyclic-aromatic and pro-oxidant mutagens.

Finally, in the early eighties the first studies were published on the application of fluorescent flow cytometry (FC) for the evaluation of antibacterial sensitivity. This technique has shown reproducible and statistically similar results as compared to those obtained by microdilution, but with performance times of $<6 \mathrm{~h}$ in fast-growing bacteria and $16 \mathrm{~h}$ in slowgrowing bacteria, such as $M$. tuberculosis [19]. Additionally, FC provides information about bacterial physiology through the evaluation of membrane permeability, metabolic activity and bacteria replication, allowing the detection of bacteria in a viable but non-culturable state (VBNC) which cannot be perceived in traditional methods [20]. FC determines bacterial viability through the reading of bacterial cells stained with specific fluorochromes that ultimately deliver information on such cell parameters. Different staining protocols have been developed, among them, SYTO9/Propidium Iodide (PI) dual staining has become the widest used protocol due to its fast-processing times and relative ease of use.

In here we aimed to evaluate the accuracy of SYTO9/PI dual staining in FC measurement of the possible antibacterial activity of Citrus latifolia and Citrus sinensis essential oils, simultaneously comparing the results to viable count method, with the purpose of establishing if FC could be a plausible test for the determination of bioactivity of these and other substances as alternatives or adjuvants of antibiotics.

\section{Results}

\subsection{Standarization}

2.1.1. Flow Cytometer Sensibility and Determination of Detection Zones

In order to standardize the appropriate gating zone for bacterial populations and to determine the sensibility of the flow cytometer for measuring changes in dead cells quantities, a series of isopropanol dilutions were prepared, and selected gates are presented as dots in side scatter plot (Figure 1a, left panel) and fluorescence plot (Figure 1a, right panel). Data appeared in a distinctive area that was drawn accordingly to previous reports [21,22]. Briefly, two oval-shaped regions are drawn in parallel and with an upward inclination to delimit dead (upper oval) and live (lower oval) bacteria. A third region covering the upper part of the ovals was drawn to measure the number of cells in an unknown state. According to our results, gating parameters were accurately set for detection of bacteria cells. Noticeably, populations with low numbers of dead cells had a marked displacement from the expected selecting gates (Figure 1b) even reaching the region of live bacteria; hence, to avoid confusing readings, $70 \%$ isopropanol was preferred as dead cells control. 

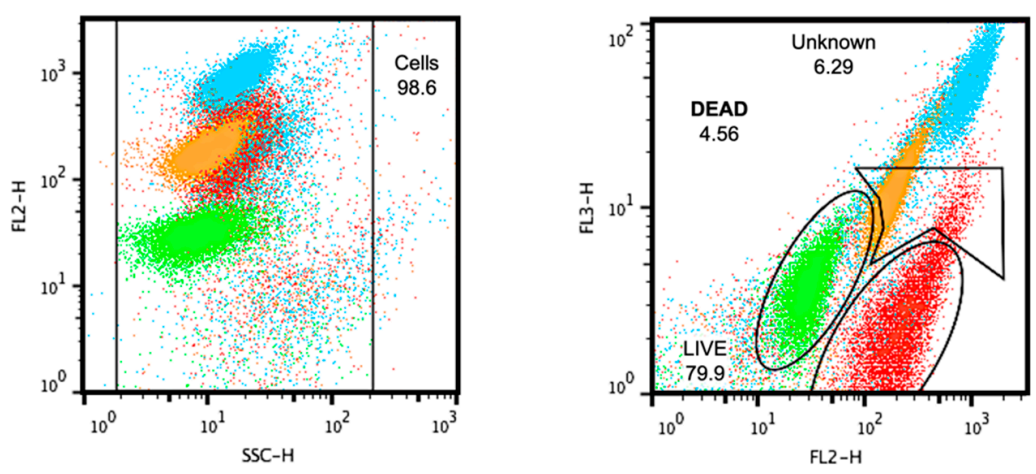

(a)

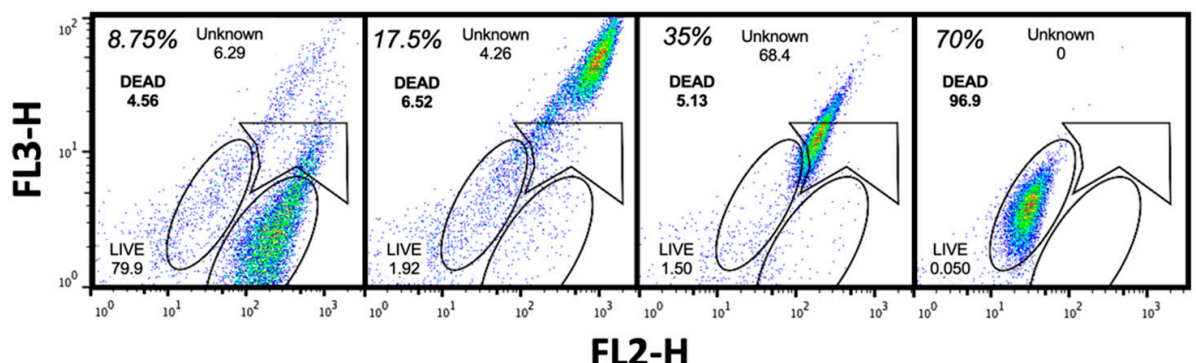

(b)

Figure 1. Dot plots of FC sensibility for dead cells detection. (a) Merged dot plots of red fluorescence (FL2-H) vs. side scatter (SSC-H) (left panel) and of green fluorescence (FL3-H) vs. red fluorescence (FL2-H) (right panel) for isopropanol dilutions at 8.75\% (red), 17.5\% (blue), 35\% (orange) and 70\% (green); (b) Dot plot of regions acquired from green fluorescence (FL3-H) vs. red fluorescence (FL2-H) for individual dilutions. Numbers represent the cell percentage with respect to the total acquired events.

\subsubsection{Determination of Live and Dead CELL Populations}

To observe whether live and dead cells populations were located into the stablished detection zones within the FC dot plots, untreated and 70\% isopropanol treated E. coli cultures were simultaneously stained with SYTO9/PI and read as described above. Figure 2 shows blue (live) and red (dead) dots that were inside the corresponding distinctive spaces in side scatter (Figure 2a) and fluorescence (Figure 2b) plots.

These treatments were denominated live (LCS) and dead (DCS) cell suspensions and constituted the live/dead controls that were prepared and simultaneously read in the experimental conditions used for EOs antibacterial determination.

\subsubsection{Standard Antibiotics}

Once the cytometer was calibrated, E. coli cultures were subjected to antibiotic treatment in suspension (treated bacterial suspensions, TBS) as a preparative test for later comparison with experimental readings. Antibiotics and its concentrations recommended by the M100 file from the CLSI were used as starting point for cytometric examination under dual staining protocol. Figure 3 shows the resulting dot plots from chloramphenicol and cefotaxime treatments. Chloramphenicol does not render a number of dead cells that changes in accordance with the utilized concentrations (Figure 3, upper panels), hence it was not an eligible as reference antibiotic. Cefotaxime treatment, although highly recommended on the M100 file, had a rather diffuse behavior with dead/live populations undefinedly distributed along the whole plotting space (Figure 3, middle panels). 


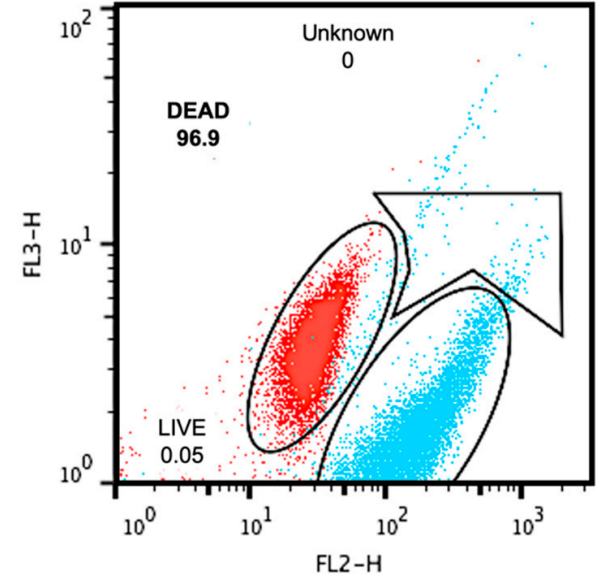

(a)

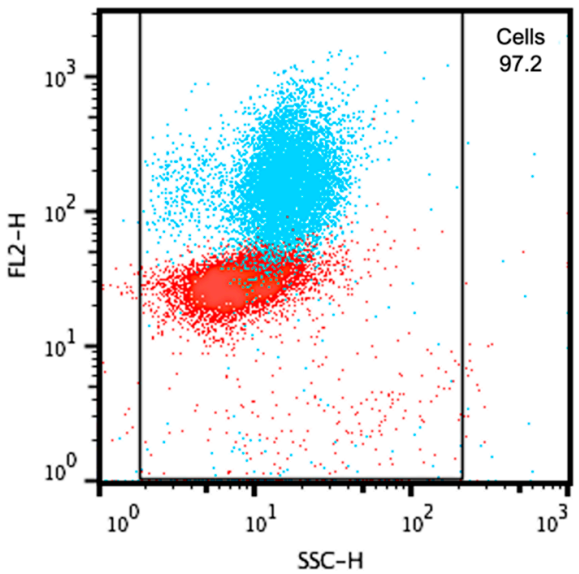

(b)

Figure 2. Dot plots of detection zones for live (blue) and dead (red) populations. (a) Dot plot of gates acquired from the red fluorescence (FL2-H) vs. side scatter or granularity (SSC-H); (b) Dot plot of gates acquired from the green fluorescence (FL3-H) vs. red fluorescence (FL2-H). Numbers represent the cell percentage with respect to the total acquired events.

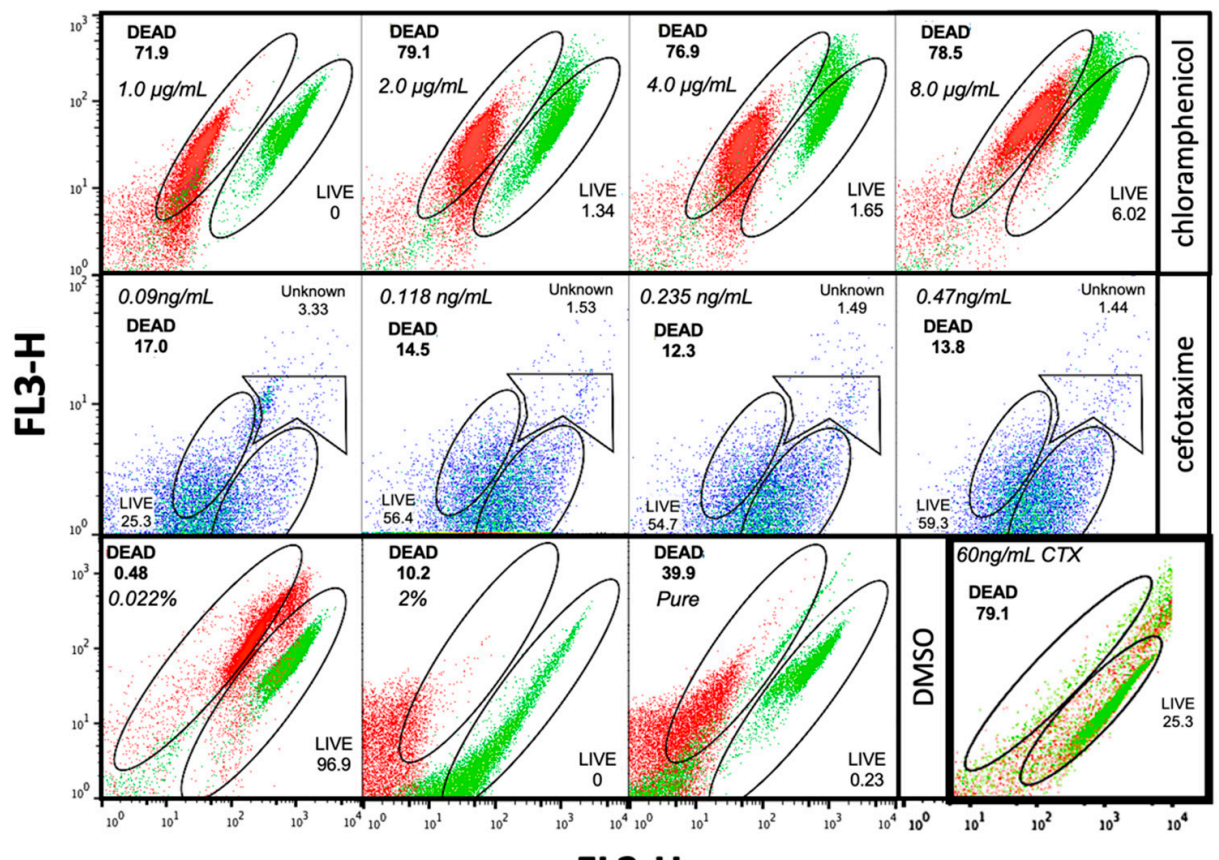

FL2-H

Figure 3. Standard antibiotics determination. Dot plots for the treatment of E. coli with chloramphenicol (upper panels), cefotaxime (middle panels) and DMSO (lower panels).

Higher concentrations of cefotaxime $(60 \mathrm{ng} / \mathrm{mL})$ seemed to redirect data of both populations into the selecting gates, nonetheless, dead and live cells regions still appeared mixed within the live cells zone (Figure 3, lower right panel).

Additionally, to elucidate if the dilutant present on the essential oils (DMSO) could interfere with the readings, two concentrations corresponding to the those used on experimental conditions and one treatment with pure DMSO were dot plotted using the same parameters. Results showed that populations treated with the dilutant were located within the expected areas and that even pure DMSO, which was not used in any experiment, had only moderate levels of toxicity on E. coli cultures (Figure 3, lower panels). 
Afterwards, to try to discern why live/dead populations readings were so disperse, cefotaxime treated cultures were stained with SYTO9/PI simultaneously and observed by epifluorescence microscopy. Figure 4 shows typical filament formation at a concentration of $15 \mathrm{ng} / \mathrm{mL}$ (Figure $4 \mathrm{~A}$ ) but not at $7.5 \mathrm{ng} / \mathrm{mL}$ (Figure $4 \mathrm{~B}$ ), images were acquired from the same field using three different channels. Filaments could not be properly measured using FC. It also can be seen that most bacteria were emitting both fluorescence colors, probably indicating an incomplete displacement of SYTO9 by PI. This phenomenon conducted to the production of a red-yellow emission causing the measurement of a single undefined population by FC that was determined as both live and dead cells. Based on these observations, we decided to test separate staining and reading both for EOs evaluation and for comparison antibiotic determination.

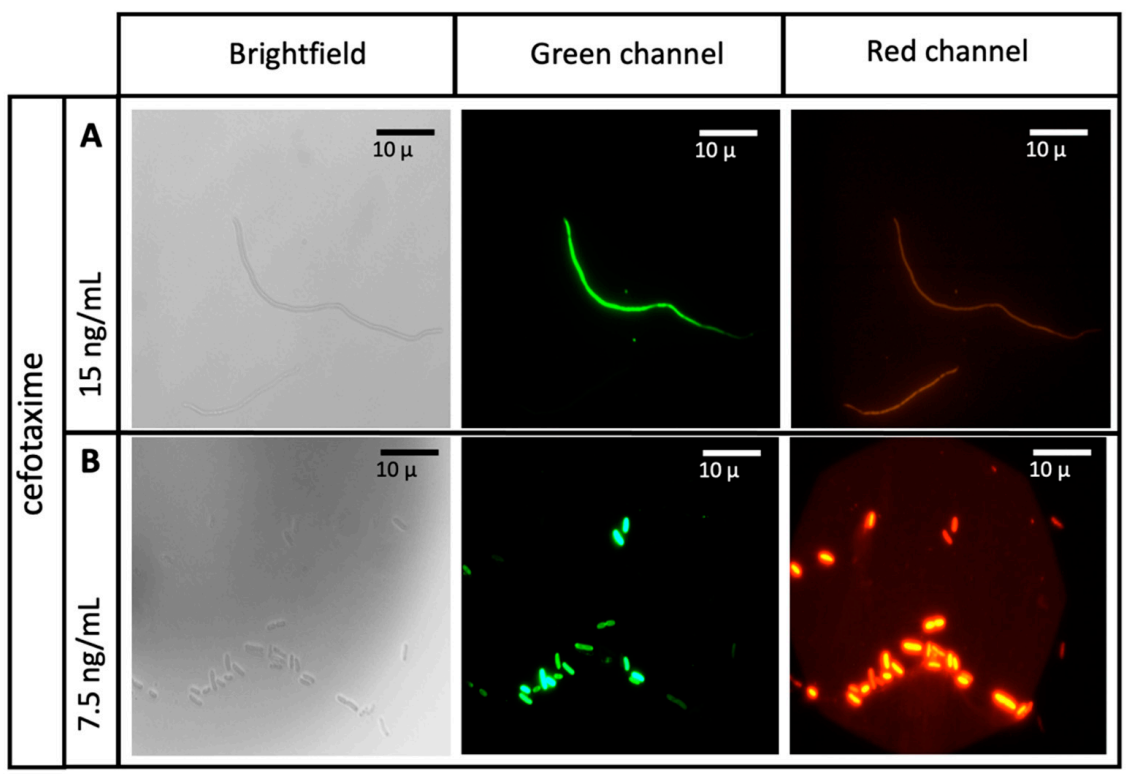

Figure 4. Epifluorescence microscopy $(100 \times)$ of cefotaxime treated E. coli cells. (A), treatment at $15 \mathrm{ng} / \mathrm{mL}(\mathbf{B})$ treatment at $7.5 \mathrm{ng} / \mathrm{mL}$.

An antibiogram was then performed due to the previously observed resistance and erratic behavior of $E$. coli on cefotaxime treatment and in order to select a suitable antibiotic for reference. Amikacin was selected since this strain resulted sensitive on the agar diffusion test from among other antibiotics (Table 1).

Table 1. Antibiogram for E. coli ATCC 25922.

\begin{tabular}{ccc}
\hline Antibiotic & $\boldsymbol{\mu g}$ & Result \\
\hline Amikacin & 30 & $\mathrm{~S}$ \\
Ampicillin & 50 & $\mathrm{R}$ \\
Carbenicillin & 2 & $\mathrm{R}$ \\
Cephalothin & 15 & $\mathrm{R}$ \\
Cefotaxime & 50 & $\mathrm{R}$ \\
Ciprofloxacin & 10 & $\mathrm{~S}$ \\
Chloramphenicol & 300 & $\mathrm{R}$ \\
Gentamicin & 1 & $\mathrm{~S}$ \\
Netilmicin & $10 \mathrm{U}$ & $\mathrm{S}$ \\
Nitrofurantoin & 30 & $\mathrm{R}$ \\
Norfloxacin & 25 & $\mathrm{R}$ \\
Ofloxacin & 30 & $\mathrm{~S}$ \\
Tetracycline & 5 & $\mathrm{R}$ \\
Sulfamethoxazole/Trimethoprim & 30 & $\mathrm{R}$ \\
\hline
\end{tabular}

${ }^{1}$ Measured in activity units (U). S = susceptible and $\mathrm{R}=$ resistant. 
Finally, several amikacin-treated E. coli cultures were stained independently with either SYTO9 or PI and then analyzed for cell populations. Figure 5 displays the resulting merged dot plots of an amikacin curve between 0.25 and $4 \mu \mathrm{g} / \mathrm{mL}$, where it can be seen that live (blue) and dead (red) cells are adequately positioned within the selecting gates (Figure 5a) and that the quantization of dead and live cells (Figure 5b) had a direct correlation with the amikacin concentration used. Thus, amikacin was utilized as the comparison antibiotic for antibacterial evaluation of the essential oils.

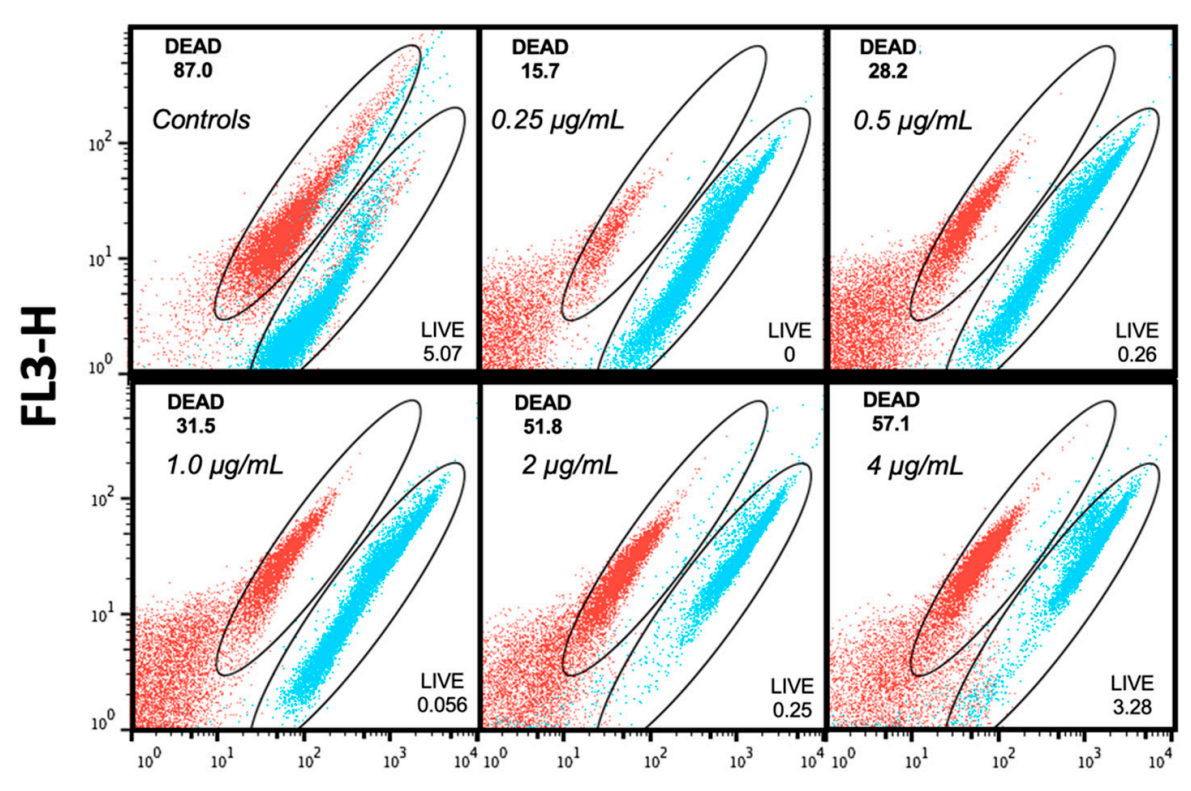

FL2-H

(a)
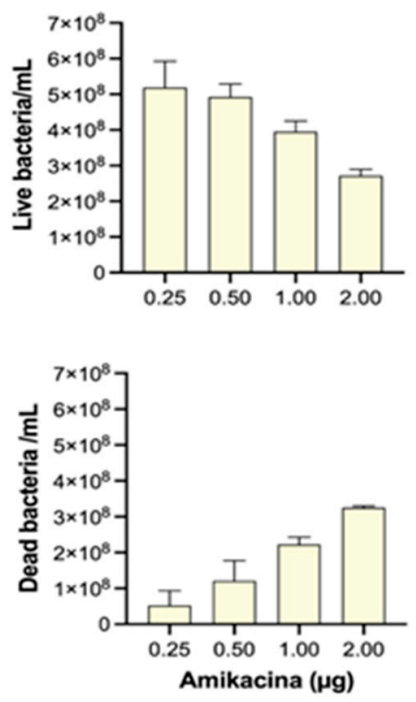

(b)

Figure 5. Dot plots of the standardization of live (blue) and dead (red) bacteria on amikacin treatment. (a) Representative dot plot of green (FL3-H) vs red (FL2-H) fluorescence of amikacin treatments; (b) Bar graphs of the calculated number of live and dead cells for amikacin doses. Bars are expressed as mean \pm S.D.

\subsection{Antibacterial Activity of Citrus Oils}

The essential oil of C. latifolia was evaluated using the FC parameters previously determined, carrying out separate staining and using the standardized comparison antibiotic (Figure 6), by means of a concentration curve between $0.25 \mu \mathrm{g} / \mathrm{mL}$ and $0.872 \mathrm{~g} / \mathrm{mL}$. From Figure 6a it can be seen that individual staining renders defined populations of live and dead cells, properly located on the expected gates, just as the pattern obtained on amikacin testing (Figure 5a). Although minimum inhibitory concentration was not reached, there was a dose-response behavior at the highest concentrations of the EO (Figure $6 \mathrm{a}, \mathrm{f}-\mathrm{h}$ ). Subsequently, the number of live and dead cells was calculated and presented as violin graphs (Figure 6b) where a greater number of live cells can be observed as compared to amikacin treatment, this indicates that there was a poor antibacterial activity of C. latifolia EO at concentrations of 0.25 to $96 \mu \mathrm{g} / \mathrm{mL}$.

Thereafter, essential oil of $C$. sinensis was evaluated under the same experimental conditions, but within a concentration curve from $0.25 \mu \mathrm{g} / \mathrm{mL}$ through $0.842 \mathrm{~g} / \mathrm{mL}$. Figure $7 \mathrm{a}$ shows well defined populations of live and dead cells within the selection gates. Minimum inhibitory concentration was not reached either, but a dose-response behavior similar to $C$. latifolia was observed at the highest concentrations (Figure $7 \mathrm{a}, \mathrm{f}, \mathrm{g}$ ). Calculated numbers of live and dead cells are presented in Figure $7 b$, where the number of live cells on EO treatments exceed amikacin registers. These results indicated that there was a low antibacterial activity of $C$. sinensis $\mathrm{EO}$ at concentrations of $0.25 \mu \mathrm{g} / \mathrm{mL}$ to $4 \mu \mathrm{g} / \mathrm{mL}$. 


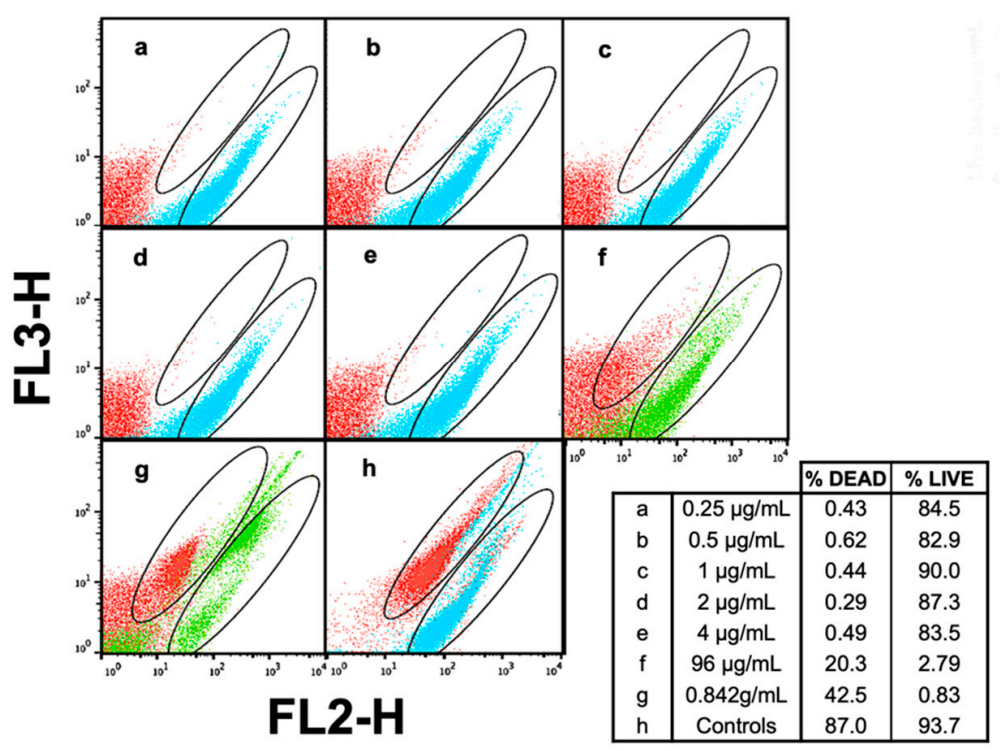

(a)

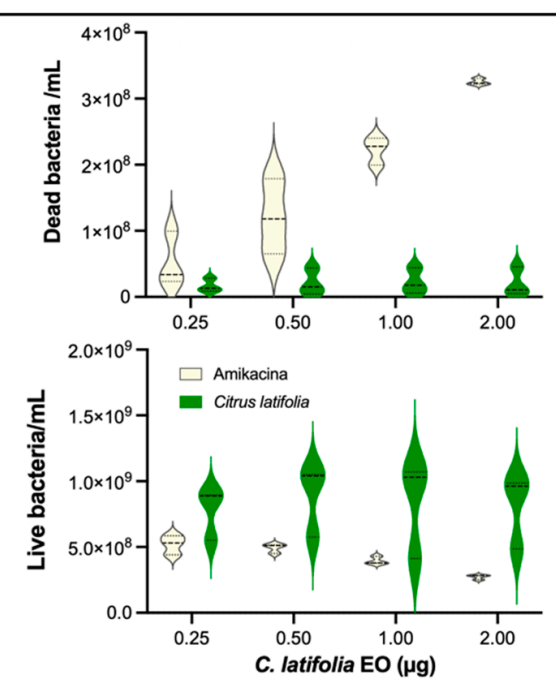

(b)

Figure 6. Evaluation of the antibacterial activity of C. latifolia EO. (a) Dot plot of green (FL3-H) vs. red (FL2-H) fluorescence readings for several concentrations of C. latifolia oil; (b) Violin graphs of the quantization of cell number for some concentrations used. Student's $t$-test: $p=0.001$ and $p=0.037$ for live and dead bacteria vs. amikacin, respectively.

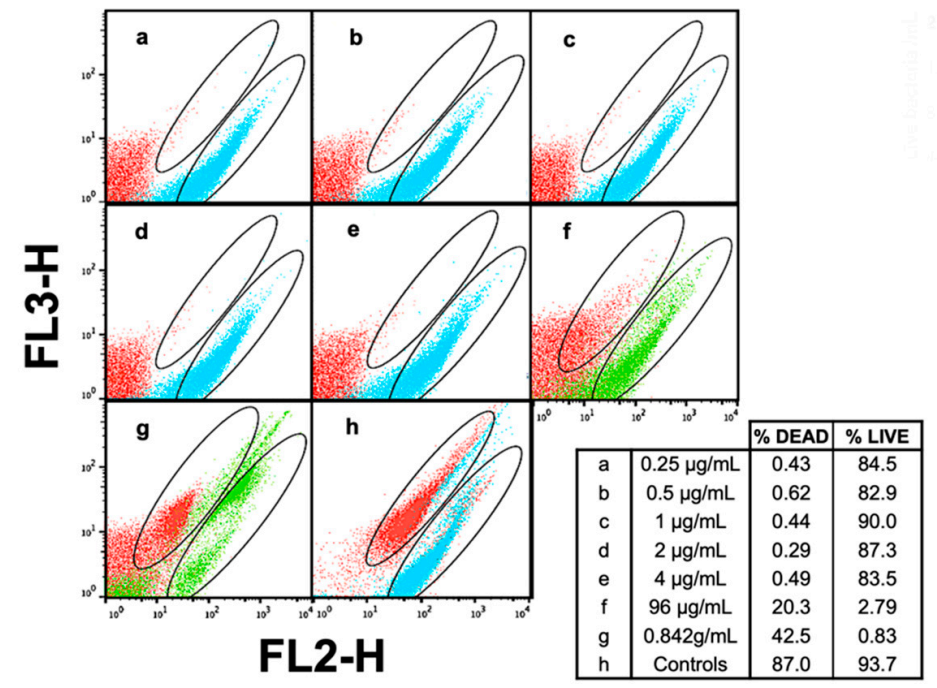

(a)
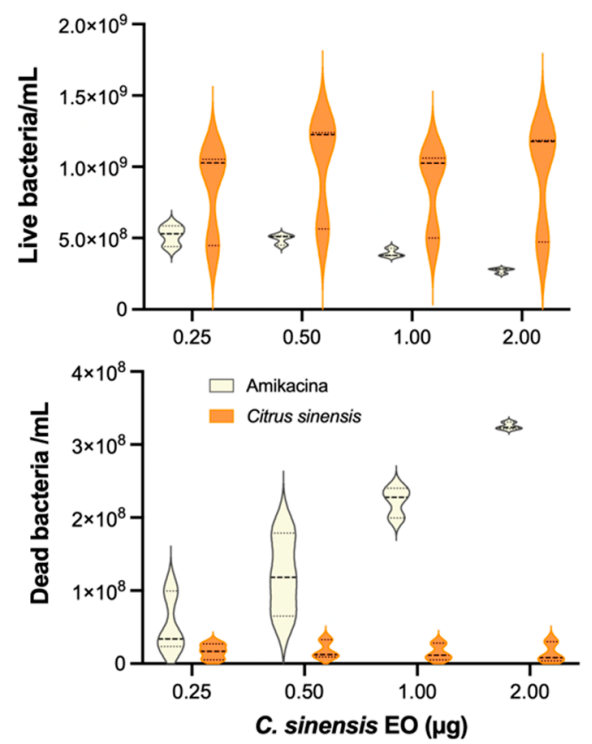

(b)

Figure 7. Evaluation of the antibacterial activity of C. sinensis EO. (a) Dot plot of green (FL3-H) vs. red (FL2-H) fluorescence gates for several concentrations of $C$. sinensis oil; (b) Violin graphs of the quantization of cell numbers in some of the used concentrations. Student's $t$-test: $p=0.003$ and $p=0.001$ for live and dead bacteria, respectively.

\subsection{Combination of Citrus Oils with Amikacin}

It has been reported that essential oils might not produce an inhibitory effect when used individually, but, when used in combination with standard antibiotics, EOs might present such effect or enhance the activity of the drug [23]. Combinations with several concentrations of amikacin were evaluated to examine a possible synergism, since citrus oils did not present an antibacterial activity by themselves at the evaluated concentrations (Figure 8). Graphs of the cell number count from FC showed that there was no synergic 
effect; on the contrary, EOs interfered with amikacin activity. This effect was produced in every concentration of amikacin used either with C. sinensis (Figure 8a) or C. latifolia (Figure 8b).
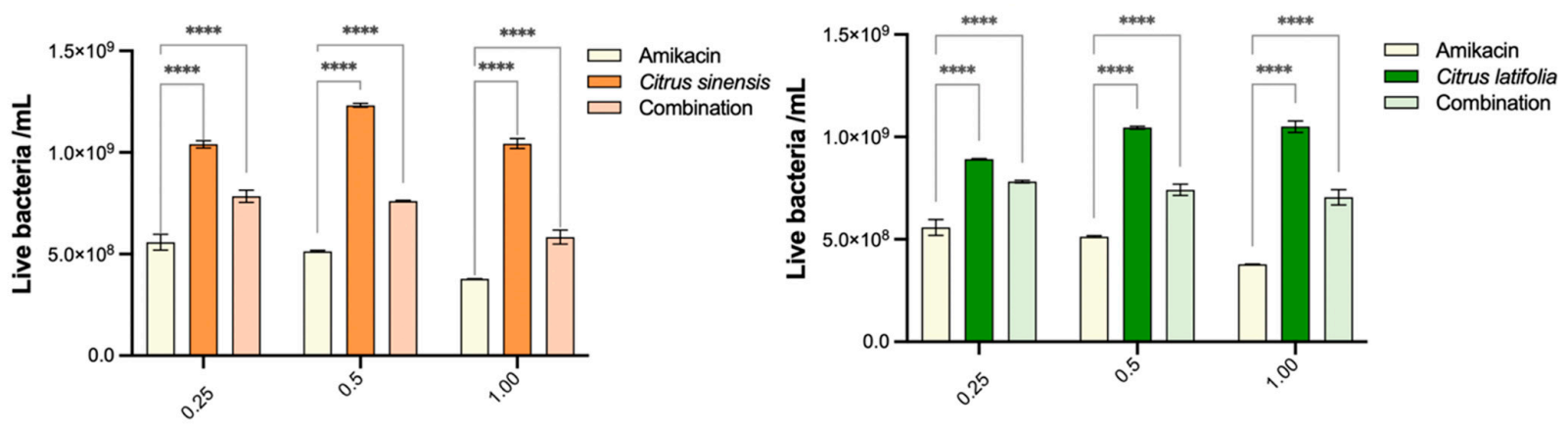

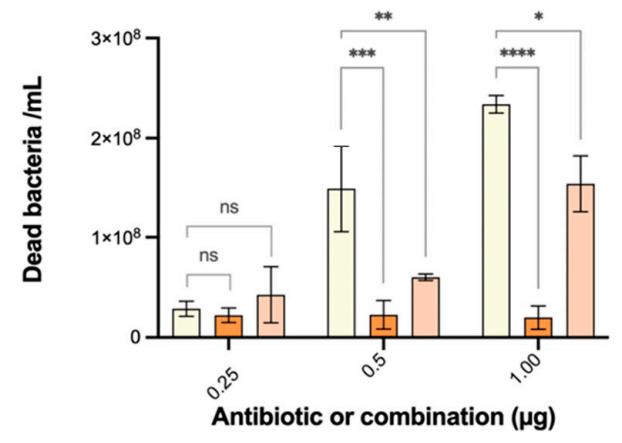

(a)

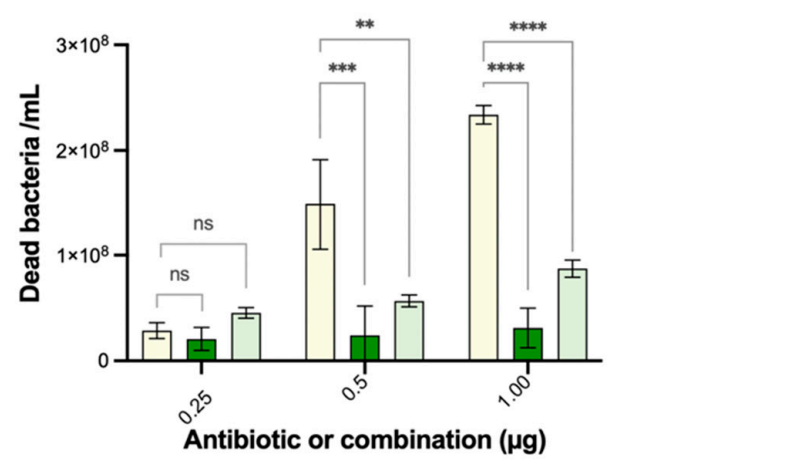

(b)

Figure 8. Evaluation of EOs combination with antibiotic. (a) Bar graph of the number of live and dead cells calculated from FC acquired gates for $C$. sinensis combined with amikacin. (b) Bar graph of the number of live and dead cells calculated from FC acquired gates for C. latifolia in combination with amikacin. Bars are expressed as mean \pm S.D. 2-way ANOVA: ns $=p>0.05{ }^{*} p \leq 0.05 ;{ }^{* *} p \leq 0.01 ;^{* * *} p \leq 0.001 ;{ }^{* * *} p \leq 0.0001$.

\subsection{Viable Counts}

To corroborate the results obtained from FC, we randomly selected individual treatments and combination from the experimental set and performed viable count assays. The number of CFUs obtained for the selected sample confirmed a poor antibacterial activity for essential oils at any of the tested concentrations (Table 2). A higher number of colonies further confirmed the inhibition of amikacin activity in the presence of the oils.

Table 2. Viable counts for some of the individual treatments and combinations.

\begin{tabular}{cccccc}
\hline Heading Concentration $(\mu \mathrm{g} / \mathrm{mL})$ & Amikacin & C. latifolia & C. sinensis & Amk + C. latifolia & Amk + C. Sinensis \\
\hline 0.25 & 800,000 & 1.19 & 1.70 & 0.96 & 1.32 \\
0.5 & 3132 & 1.52 & 1.21 & 0.83 & 0.94 \\
1.0 & 0 & 1.40 & 1.70 & 0.28 & 0.33 \\
\hline
\end{tabular}

Data are CFUs $\times 10^{7}$ except for amikacin (Amk).

\section{Discussion}

The use of natural origin compounds with antibacterial properties is an excellent alternative to avoid adverse effects of synthetic molecules and the bacterial resistance to them. A rapid and reliable diagnosis is a key strategy to reduce inappropriate antibiotic prescription, which is the main cause of antibacterial resistance [22,24]. Standard antibacterial susceptibility evaluation methods require long times to obtain results ( $24 \mathrm{~h}$ to $1 \mathrm{month}$ ). Due to this, different techniques have been developed to generate results comparable to those obtained by standard methods, but in less time, such as those obtained by the flow 
cytometry (6-16 h). We evaluated the antibacterial activity of citrus oils by this technique; however, we detected some limitations such as the observation of a region of intermediate states called "unknown population" [25] when counterstaining with SYTO9/PI, and a red-yellow fluorescence by microscopy, specifically in the treatments carried out with cefotaxime in E. coli.

Propidium iodide is a fluorophore with high affinity for DNA and RNA which only goes through intact permeable membranes and its combination with a fluorophore diffusing intact non-permeable membranes allows the counting of global cell number. Dual staining of SYTO9/PI is still widely used for the evaluation of antibacterial activity in different areas, nonetheless, its performance and effectivity are not yet clear and neither its effects on bacteria physiology. Several factors should be taken into account for a correct use of this dual staining system such as fluorochrome affinity, physiological state of cells to be stained and, incubation temperature and time. For instance, it is known that E. coli is more resistant to SYTO9 penetration than Gram positive bacteria due to cell membrane characteristics. Previous studies have shown that SYTO9 penetrates the cell in a continuous manner, meanwhile PI does it through continuous cytoadherence and that properties of the membrane could be altered by the penetration of one or both fluorochromes. On the other hand, false cell mortality signals could be displayed upon PI staining as a result of a high membrane potential, which might not correlate with culture observations due to a viable but non-culturable state (VBNC). Considering all these factors is of the uttermost importance for an accurate interpretation of FC results [26,27].

Besides, fluorochrome retention during the dynamic process of binding, release and competence for DNA binding sites [25] and the consequent increase in green fluorescence absorption by PI (fluorescence energy transfer or FRET) on suboptimal concentrations, could affect either fluorochrome or background signals. Hence, an adequate proportion with each other fluorochrome, and with the DNA content, could minimize such interference [26].

Filaments observed at low cefotaxime concentrations, could be due to the inhibition of PBP3 protein as an initial response in E. coli ATCC 25922. This protein is involved in peptidoglycan crosslinking during cell division, as described by Kjeldsen et al. in E. coli MG1655 [28]. However, at high cefotaxime concentrations, CTX-M-1 expression reached high levels, and the antibiotic was hydrolyzed, being unable to further bind to PBP3 [28].

MIC could not be obtained by flow cytometry because less than $80 \%$ of dead bacteria and a high rate of bacterial debris were detected at the highest evaluated concentration of amikacin. This could be due to the prolonged exposure time to the antibiotic which might have caused bacterial lysis; therefore, it is necessary to perform time-mortality curves to obtain optimal incubation times where antibiotic exerts its effect without disrupting bacterial integrity.

In regard to the treatment with essential oils, Frassinetti et al. [15] found an antibacterial activity from C. sinensis on E. coli by measuring cultures optical density, according to their results there was over $90 \%$ reduction in absorbance at $25 \mu \mathrm{g} / \mathrm{mL}$, and raised the conclusion that time of exposure to EOs could be a determining factor to observe its antibacterial activity. Similarly, Dhiman et al. [29] used microdilution and disc diffusion method (DDM) to show that methanolic extract of $C$. sinensis peel had antibacterial activity on E. coli with a minimum inhibitory concentration of $0.78 \mu \mathrm{g} / \mathrm{mL}$ and a minimum bactericidal concentration of $6.25 \mu \mathrm{g} / \mathrm{mL}$. On the other hand, Das et al. [30] showed that the methanolic extract of $C$. latifolia had antimicrobial inhibitory activity against E. coli in agar well diffusion method. Analogously, Everton et al. [31] found that the EO of C. latifolia had activity against $E$. coli and $S$. aureus on DDM.

In contrast, we observed that percentages $\geq 80 \%$ of dead bacteria were not obtained by flow cytometry, even at concentrations of $96 \mu \mathrm{g} / \mathrm{mL}, 8.720 \mathrm{mg} / \mathrm{mL}$ and $0.872 \mathrm{~g} / \mathrm{mL}$ of C. latifolia $\mathrm{EO}$ and $96 \mu \mathrm{g} / \mathrm{mL}$ and $0.842 \mathrm{~g} / \mathrm{mL}$ of C. sinensis $\mathrm{EO}$.

Our results are more similar to those obtained by Adham et al. [32] who evaluated the antibacterial activity of peel ethanolic extracts and juice from four citrus species by 
DDM and found that $C$. sinensis had poor activity for Gram positive bacteria and null effect on Gram negative bacteria. Additionally, Tran et al. [33] results showed no activity of the C. latifolia EO on E. coli and other Gram negative bacteria such as S. typhimurium and $P$. aeruginosa, as opposed to the antibacterial effect observed on Gram positive bacteria like Bacillus cereus, Listeria monocytogenes and Staphylococcus aureus.

Although the results may seem divergent, it can be seen that, in general, citrus EOs have poor or no antibacterial effects against Gram negative bacteria, probably due to cell wall and membrane differences in contrast to Gram positive. Another difference between our results and the literature is the type of extraction, while we tested the essential oils from peel, other works were carried out using ethanolic extracts, methanolic extracts or juice. Differences have also been reported depending on the part of the plant from which these products are obtained, such as peel, seed, pulp, leaves, etc., which consequently yields multiple compositions that are unique on each research. On the other hand, it has been reported about the differences depending on the origin of the crops and the harvest time of the citrus fruits, among other intrinsic factors. Finally, it has also been reported that essential oils with high concentration of hydrocarbon terpenes may be more likely to have low antibacterial activity $[5,34]$.

Despite these observations, most of the biological properties of Citrus genus have been attributed to limonene, one of its main components and a hydrocarbon terpene. For instance, in Citrus sinensis Osbeck cv. Newhall limonene is the main component (85.32\%), and an antibacterial effect was shown at concentrations of $1.56 \mu \mathrm{L} / \mathrm{mL}, 0.78 \mu \mathrm{L} / \mathrm{mL}$, $1.56 \mu \mathrm{L} / \mathrm{mL}$ and $3.13 \mu \mathrm{L} / \mathrm{mL}$, against S. cerevisiae, E. coli, B. subtilis and S. aureus; respectively. However, when limonene was evaluated individually, MIC values were $15.68 \mu \mathrm{L} / \mathrm{mL}$ (S. cerevisiae and E. coli) and $3.92 \mu \mathrm{L} / \mathrm{mL}$ (B. subtilis and S. aureus). In addition, authors observed that coexistent components at lower percentages within this EO, such as $\alpha$-pinene, linalool, decanal, terpineol, citral and nonanal, presented higher antibacterial activity as compared to limonene [35]. Our results are congruent with this study since the EOs used are composed mainly by limonene and had poor antibacterial activity.

Factors such as functional groups of active components and their synergistic interactions will be decisive in the activity of EOs, since it has been shown that the effect of individual components differs from the one obtained in combination within the EOs, since each component exerts a different mechanism of action in the bacteria. This is the main reason for EOs to be proposed as new antibacterial compounds since it would be more difficult for bacteria to generate resistance to all of its components [35].

On the other hand, the decrease in the activity of amikacin in combination with EOs could be due to the alteration of its solubility by the presence of hydrophobic components (D-limonene, $\beta$-thujene, $\alpha$-pinene, $\beta$-pinene, $\alpha$-myrcene and $\gamma$-terpinene). The solubility of amikacin in water is $50 \mathrm{mg} / \mathrm{mL}$ and is much less soluble in DMSO $(<1 \mathrm{mg} / \mathrm{mL})$ present in the EOs dilutions [36], indicating that the solubility of amikacin decreases in the presence of organic solvents.

Finally, although there are currently automated systems for the evaluation of antibacterial susceptibility that provide results in time ranges comparable to flow cytometry, this technique has the advantage of determining viability of culturable and nonculturable (VBNC) bacteria through measurement of parameters such as membrane integrity and metabolic activity. We found that evaluation of antibacterial susceptibility through dual staining presents certain limitations that were overcome by separation of stains.

\section{Materials and Methods}

\subsection{Reagents and Strains}

Reference strain Escherichia coli ATCC 25922 (Microbiologics ${ }^{\circledR}$, Saint Cloud, MN, USA) was used as recommended by the CLSI. Mueller-Hinton broth and agar, Trypticasein-Soy agar, Nutrient agar and Blood agar were acquired from Becton Dickinson (BD, Franklin Lakes, NJ, USA). Soft agar was prepared with $0.6 \mathrm{~g}$ agar base (BD, Franklin Lakes, NJ, USA) and $0.6 \mathrm{~g} \mathrm{NaCl}$ (Promega, Madison, WI, USA). 
Saline solution $(0.85 \% \mathrm{NaCl})$ (J.T. Baker, Phillipsburg, NJ, USA) was used for washing and maintaining cultures. 2\% DMSO (J.T. Baker, Phillipsburg, NJ, USA) was used as dissolvent for essential oils. Antibiotics cloramphenicol, cefotaxime, and amikacin were purchased from AMSA (Coyoacan, CDMX, Mexico).

LIVE/DEAD ${ }^{\circledR}$ BacLight $^{\mathrm{TM}}$ Bacterial Viability and Counting kit (Cat. L34856, Thermo Fisher, Waltham, MA, USA) was used for sample staining.

McFarland turbidity standard was prepared by mixing $0.05 \mathrm{~mL}$ of $1.175 \%$ barium chloride dihydrate $\left(\mathrm{BaCl}_{2} \bullet 2 \mathrm{H}_{2} \mathrm{O}\right)$, with $9.95 \mathrm{~mL}$ of $1 \%$ sulfuric acid $\left(\mathrm{H}_{2} \mathrm{SO}_{4}\right)$. All standard preparations were verified in a Coleman spectrophotometer at $600 \mathrm{~nm}$ (abs. 0.063) previous to be used.

\subsection{Essential Oils of Citrus sinensis and Citrus latifolia}

EOs of $C$. sinensis and C. latifolia were obtained by hydro-distillation of the peel, kindly donated by Frutech International Corporation Cargee Additives, Montemorelos Nuevo León, México, for Dr. Marisela González Ávila. Its composition was previously described by Ruiz et al. [17].

\subsection{Calibrated Bacterial Solutions (CBS)}

E. coli strain was seeded in trypticasein-soy agar for $24 \mathrm{~h}$ at $37^{\circ} \mathrm{C}$. Bacteria were then resuspended in SS and compared to $0.5 \mathrm{McF}$ arland standard in a spectrophotometer (Junior II model 620, Coleman, Maywood, IL, USA).

\subsection{Antibacterial Agents}

Seven serial dilutions of cefotaxime were prepared by duplicate for flow cytometry measurements, and three dilutions for fluorescence microscopy, according to CLSI recommendations [37]. Five amikacin dilutions were prepared by duplicate to be used as CLSI recommended reference antibiotic. Essential oils of $C$. latifolia and $C$. sinensis were serially diluted in $2 \%$ DMSO to reach same concentration as amikacin, so bacterial susceptibility could be compared. Table 3 shows the whole set of preparations.

Table 3. Antibacterial concentrations $(\mu \mathrm{g} / \mathrm{mL})$ used for evaluation of E. coli strain.

\begin{tabular}{ccccc}
\hline Cloramphenicol & Cefotaxime & Amikacin & C. latifolia & C. sinensis \\
\hline 1 & $7.5 \times 10^{-3}$ & 0.25 & 0.25 & 0.25 \\
2 & $15 \times 10^{-3}$ & 0.5 & 0.5 & 0.5 \\
4 & $60 \times 10^{-3}$ & 1 & 1 & 1 \\
8 & $0.118 \times 10^{-3}$ & 2 & 2 & 2 \\
& $0.235 \times 10^{-3}$ & 4 & 4 & 4 \\
& $0.47 \times 10^{-3}$ & & 96 & 96 \\
& & & $8.720 \times 10^{3}$ & $8.420 \times 10^{7}$ \\
\hline
\end{tabular}

\subsection{Combination Assays}

For testing possible effects of EOs in combination with antibiotic, three dilutions of amikacin were mixed with $1 \mu \mathrm{g} / \mathrm{mL}$ of $C$. sinensis or $C$. latifolia essential oils as shown in Table 4.

Table 4. Antibacterial + EOs concentrations $(\mu \mathrm{g} / \mathrm{mL})$ used for combination essays.

\begin{tabular}{ccc}
\hline Amikacin & C. latifolia & C. sinensis \\
\hline 1 & 1 & - \\
0.5 & 1 & - \\
0.25 & 1 & - \\
1 & - & 1 \\
0.5 & - & 1 \\
0.25 & - & 1 \\
\hline
\end{tabular}




\subsection{Treated Bacterial Suspensions (TBS)}

$1 \mathrm{~mL}$ of $0.5 \mathrm{McF}$ arland CBS was resuspended in $1 \mathrm{~mL}$ of Mueller-Hinton broth. Then, $250 \mu \mathrm{L}$ of this suspension was added to either antibiotics, EOs alone or EOs + amikacin mixtures and incubated at $37^{\circ} \mathrm{C}$ for $3 \mathrm{~h}$ under $70 \mathrm{rpm}$ agitation.

After incubation each sample or TBS was centrifuged at $470 \mathrm{~g}$ for $5 \mathrm{~min}$ and supernatant was discarded. Pellet was washed twice with saline solution (SS) and finally resuspended in $1 \mathrm{mLSS}$.

\subsection{Flow Cytometry}

Fluorochrome stock solutions were prepared by adding $3 \mu \mathrm{L}$ of SYTO9 $(5 \mathrm{mM})$ or $3 \mu \mathrm{L}$ of PI $(20 \mathrm{mM})$ to $97 \mu \mathrm{L}$ of distilled water.

For live (LCS) and dead (DCS) cell suspensions, $1 \mathrm{~mL}$ of CBS was centrifuged at $12,700 \times \mathrm{g}$ for $5 \mathrm{~min}$ and resuspended either in $1 \mathrm{~mL}$ of SS for LCS or in $1 \mathrm{~mL}$ of $70 \%$ isopropanol for DCS. Staining was performed by mixing $178 \mu \mathrm{L}$ of LCS or DCS with $10 \mu \mathrm{L}$ of SYTO9 or PI stocks, respectively. Mixtures were incubated at room temperature for 15 min and read with the flow cytometer (FACScalibur, Beckton Dickinson, Franklin Lakes, NJ, USA).

Flow cytometer excitation laser was $488 \mathrm{~nm}$ in wavelength and fluorescence emissions were collected on red and green channels. LCS stained with SYTO9 and DCS stained with PI were used to locate the corresponding bacterial populations and to standardize most adequate cytometric parameters, avoiding emission spectra superposition. Frontal dispersion, lateral dispersion and fluorescence were acquired with logarithmic signal amplification. First, lateral and frontal dispersion amplifications were configured, followed by green fluorescence amplification to evidence live bacteria, and finally, red fluorescence amplification was tuned to show dead bacteria. Live and dead bacteria regions in the dot plots were defined using the parameters of SSC: 430, FL1: 659, FL2: 520 and FL3: 55. For dual staining, samples were prepared by mixing both dead and live suspensions ( $10 \mu \mathrm{L}$ each) and incubating with SYTO9/PI (10 $\mu \mathrm{L}$ each) in SS for a final volume of $200 \mu \mathrm{L}$ during $15 \mathrm{~min}$ at room temperature.

\subsection{Fluorescence Microscopy}

TBS was resuspended in $100 \mu \mathrm{L}$ of SS with $10 \mu \mathrm{L}$ SYTO9 and these mixtures were incubated for $15 \mathrm{~min}$ at room temperature before smearing them on slides (live bacteria). Similarly, isopropanol and cefotaxime treated samples were dual stained with SYTO9/PI to visualize fluorochrome acquisition and morphological changes using an Axio Imager.A2 microscope with an integrated camera (Axiocam ICc5, Carl Zeiss Microscopy GmbH, Jena, Germany).

\subsection{Viable Count}

$10 \mu \mathrm{L}$ of all TBS (amikacin, EOs, combinations and isopropanol) and untreated bacteria were resuspended in soft agar and immediately added to nutritive agar. After incubation for $24 \mathrm{~h}$ at $37^{\circ} \mathrm{C}$, the number of colony-forming units (CFUs) in each plate were counted on a colony counter (AccuLite Colony Counter Model 133-8002, Fisher Scientific International Inc., Hampton, NH, USA) and cell number were adjusted according to the dilution factor.

\subsection{Statistical Analysis}

Data were analyzed using GraphPad Prism and SPSS. Statistically significative differences between essential oils and amikacin were determined by student's $t$-test. Values with $p<0.05$ were considered significant. Comparisons of EOs in combination with amikacin were made through two-way ANOVA analysis, $p<0.05$ were considered significant.

\section{Conclusions}

Flow cytometry is a useful tool in the evaluation of bacterial susceptibility because it shows reproducible results as compared with viable count technique, but with faster 
processing times. Even so, we consider that research with FC could also be focused on the development of new dual staining systems for bacterial viability since this field is still scarcely explored and existing stains have not been fully standardized, still having certain limitations. This was the case for SYTO9/PI dual staining, where the reliability of results was compromised by its inability to discriminate between viable and non-viable bacteria due to the displacement of populations (live and dead) towards an "unknown" region by the retention of both fluorochromes within cells.

Under the experimental conditions and staining settings found in this study, the essential oils of C. latifolia and C. sinensis presented poor antibacterial activity on E. coli, perhaps due to the short exposure time.

Interestingly, EOs presented an antagonistic effect against amikacin that may be due to a solubility change in the presence of organic components such as D-limonene, $\beta$-thujene, $\alpha$-pinene, $\beta$-pinene, $\alpha$-myrcene and $\gamma$-terpinene.

To our best knowledge, this is one of the fewest works that follows a series of systematic standardization steps to found adequate conditions for the flow cytometer acquiring of bacteria, fluorochrome concentration, determination of suitable comparison antibiotics and exposition times to antibiotics, to be used in the determination of antibacterial activity.

Even though this is a preliminary study where FC settings were standardized for a unique E. coli strain, the experimental development reported in here could be applied on future studies on Gram positive and/or Gram negative strains/species by contrasting the results against microdilution method. Additionally, it would be of interest to perform studies directed to prove the antagonism hypothesis of citrus EOs against amikacin.

Author Contributions: Conceptualization, N.G.N.-V., A.A.G.-V., J.D.T.-G. and N.J.R.-P.; Data curation, N.G.N.-V., A.A.G.-V. and J.S.-N.; Formal analysis, J.S.-N.; Funding acquisition, J.D.T.-G.; Investigation, N.G.N.-V., A.A.G.-V. and N.J.R.-P.; Methodology, N.G.N.-V. and A.A.G.-V.; Project administration, N.J.R.-P.; Resources, M.G.-Á.; Supervision, N.G.N.-V. and N.J.R.-P.; Visualization, M.G.-Á., J.S.-N. and J.D.T.-G.; Writing-original draft, M.G.-Á., J.S.-N., J.D.T.-G. and N.J.R.-P.; Writing—review \& editing, M.G.-Á., J.D.T.-G. and N.J.R.-P. All authors have read and agreed to the published version of the manuscript.

Funding: This research was partially funded by Hospital Juárez de México, protocol code: HJM 0575/19I.

Institutional Review Board Statement: The study was approved by the Institutional Review Boards (Research, Ethics and Biosecurity Committees) of Hospital Juárez de México (protocol code: HJM 0575/19I, approved on 1 June 2018).

Acknowledgments: Authors would like to acknowledge B.D. Luz Yesenia Jiménez Rojas for the kind donation of E. coli strain. We also acknowledge M. en C. Alejandra Espinosa Bonilla from Escuela Nacional de Ciencias Biológicas for her valuable technical assistance on FC acquisitions.

Conflicts of Interest: The authors declare no conflict of interest. The funders had no role in the design of the study; in the collection, analyses, or interpretation of data; in the writing of the manuscript, or in the decision to publish the results.

\section{References}

1. Ventola, C.L. The antibiotic resistance crisis: Part 1: Causes and threats. Pharm. Ther. 2015, 40, 277.

2. Swamy, M.K.; Akhtar, M.S.; Sinniah, U.R. Antimicrobial properties of plant essential oils against human pathogens and their mode of action: An updated review. Evid.-Based Complement. Altern. Med. 2016, 2016, 3012462. [CrossRef] [PubMed]

3. Yap, P.S.X.; Yiap, B.C.; Ping, H.C.; Lim, S.H.E. Essential oils, a new horizon in combating bacterial antibiotic resistance. Open Microbiol. J. 2014, 8, 6. [CrossRef] [PubMed]

4. Bakkali, F.; Averbeck, S.; Averbeck, D.; Idaomar, M. Biological effects of essential oils-A review. Food Chem. Toxicol. 2008, 46, 446-475. [CrossRef] [PubMed]

5. Bassolé, I.H.N.; Juliani, H.R. Essential oils in combination and their antimicrobial properties. Molecules 2012, 17, 3989-4006. [CrossRef] [PubMed]

6. Arce, A.; Soto, A. Citrus essential oils: Extraction and deterpenation. Tree For. Sci. Biotechnol. 2008, 2, 1-9.

7. Nazzaro, F.; Fratianni, F.; De Martino, L.; Coppola, R.; De Feo, V. Effect of essential oils on pathogenic bacteria. Pharmaceuticals 2013, 6, 1451-1474. [CrossRef] [PubMed] 
8. Costa, R.; Bisignano, C.; Filocamo, A.; Grasso, E.; Occhiuto, F.; Spadaro, F. Antimicrobial activity and chemical composition of Citrus aurantifolia (Christm.) Swingle essential oil from Italian organic crops. J. Essent. Oil Res. 2014, 26, 400-408. [CrossRef]

9. Lopez-Romero, J.C.; González-Ríos, H.; Borges, A.; Simões, M. Antibacterial effects and mode of action of selected essential oils components against Escherichia coli and Staphylococcus aureus. Evid.-Based Complement. Altern. Med. 2015, $2015,795435$. [CrossRef] [PubMed]

10. Kummer, R.; Fachini-Queiroz, F.C.; Estevão-Silva, C.F.; Grespan, R.; Silva, E.L.; Bersani-Amado, C.A.; Cuman, R.K.N. Evaluation of anti-inflammatory activity of Citrus latifolia Tanaka essential oil and limonene in experimental mouse models. Evid.-Based Complement. Altern. Med. 2013, 2013, 859083. [CrossRef]

11. Lewis, K. Platforms for antibiotic discovery. Nat. Rev. Drug Discov. 2013, 12, 371-387. [CrossRef]

12. Narang, N.; Jiraungkoorskul, W. Anticancer activity of key lime, Citrus aurantifolia. Pharmacogn. Rev. 2016, 10, 118.

13. Chaudhari, S.Y.; Ruknuddin, G.; Prajapati, P. Ethno medicinal values of Citrus genus: A review. Med. J. Dr. DY Patil Univ. 2016, 9, 560. [CrossRef]

14. Jafarzadeh, M.; Arman, S.; Pour, F.F. Effect of aromatherapy with orange essential oil on salivary cortisol and pulse rate in children during dental treatment: A randomized controlled clinical trial. Adv. Biomed. Res. 2013, 2, 1-7.

15. Frassinetti, S.; Caltavuturo, L.; Cini, M.; Della Croce, C.; Maserti, B. Antibacterial and antioxidant activity of essential oils from Citrus spp. J. Essent. Oil Res. 2011, 23, 27-31. [CrossRef]

16. Singh, P.; Shukla, R.; Prakash, B.; Kumar, A.; Singh, S.; Mishra, P.K.; Dubey, N.K. Chemical profile, antifungal, antiaflatoxigenic and antioxidant activity of Citrus maxima Burm. and Citrus sinensis (L.) Osbeck essential oils and their cyclic monoterpene, DL-limonene. Food Chem. Toxicol. 2010, 48, 1734-1740. [CrossRef]

17. Ruiz-Pérez, N.J.; González-Ávila, M.; Sánchez-Navarrete, J.; Toscano-Garibay, J.D.; Moreno-Eutimio, M.A.; Sandoval-Hernández, T.; Arriaga-Alba, M. Antimycotic activity and genotoxic evaluation of Citrus sinensis and Citrus latifolia essential oils. Sci. Rep. 2016, 6, 25371. [CrossRef]

18. Toscano-Garibay, J.; Arriaga-Alba, M.; Sánchez-Navarrete, J.; Mendoza-García, M.; Flores-Estrada, J.; Moreno-Eutimio, M.; Espinosa-Aguirre, J.; González-Ávila, M.; Ruiz-Pérez, N. Antimutagenic and antioxidant activity of the essential oils of Citrus sinensis and Citrus latifolia. Sci. Rep. 2017, 7, 11479. [CrossRef]

19. Zhu, C.; Liu, Y.; Hu, L.; Yang, M.; He, Z.-G. Molecular mechanism of the synergistic activity of ethambutol and isoniazid against Mycobacterium tuberculosis. J. Biol. Chem. 2018, 293, 16741-16750. [CrossRef] [PubMed]

20. Kumar, S.S.; Ghosh, A.R. Assessment of bacterial viability: A comprehensive review on recent advances and challenges. Microbiology 2019, 165, 593-610. [CrossRef] [PubMed]

21. Thermofisher. LIVE/DEAD ${ }^{\circledR}$ BacLight ${ }^{\mathrm{TM}}$ Bacterial Viability and Counting Kit Manual. Available online: https://assets. thermofisher.com/TFS-Assets/LSG/manuals/mp34856.pdf (accessed on 31 July 2021).

22. Thornton, R.G.W.; Gilmour, L.; Alsharif, R. Evaluation of Yeast Viability and Concentration during Wine Fermenta-Tion Using Flow Cytometry. Available online: http:/ / www.bdbiosciences.com/immunocytometry_systems/application_notes/ (accessed on 30 June 2021).

23. Moussaoui, F.; Alaoui, T. Evaluation of antibacterial activity and synergistic effect between antibiotic and the essential oils of some medicinal plants. Asian Pac. J. Trop. Biomed. 2016, 6, 32-37. [CrossRef]

24. Robertson, J.; McGoverin, C.; Vanholsbeeck, F.; Swift, S. Optimisation of the protocol for the LIVE/DEAD®BacLightTM bacterial viability kit for rapid determination of bacterial load. Front. Microbiol. 2019, 10, 801. [CrossRef]

25. Berney, M.; Hammes, F.; Bosshard, F.; Weilenmann, H.-U.; Egli, T. Assessment and interpretation of bacterial viability by using the LIVE/DEAD BacLight Kit in combination with flow cytometry. Appl. Environ. Microbiol. 2007, 73, 3283-3290. [CrossRef]

26. Deng, Y.; Wang, L.; Chen, Y.; Long, Y. Optimization of staining with SYTO 9/propidium iodide: Interplay, kinetics and impact on Brevibacillus brevis. BioTechniques 2020, 69, 88-98. [CrossRef] [PubMed]

27. Rosenberg, M.; Azevedo, N.F.; Ivask, A. Propidium iodide staining underestimates viability of adherent bacterial cells. Sci. Rep. 2019, 9, 6483. [CrossRef]

28. Kjeldsen, T.S.; Sommer, M.O.; Olsen, J.E. Extended spectrum $\beta$-lactamase-producing Escherichia coli forms filaments as an initial response to cefotaxime treatment. BMC Microbiol. 2015, 15, 63. [CrossRef]

29. Dhiman, A.; Nanda, A.; Ahmad, S.; Narasimhan, B. In vitro antimicrobial status of methanolic extract of Citrus sinensis Linn. fruit peel. Chron. Young Sci. 2012, 3, 204-208. [CrossRef]

30. Das, A.; Vasundraa, M.; Vinotha, V.; Sanofer, P.; Bindhu, J. Evaluation of Phytochemical Analysis and Antimicrobial Activity of Citrus Latifolia Peel Extract. Indian J. Public Health Res. Dev. 2019, 10, 18-23. [CrossRef]

31. Everton, G.O.; Teles, A.M.; Mouchrek, A.N.; Mouchrek Filho, V.E. Extraction, chemical characterization and antimicrobial potency of essential oil of Tahiti lemon (Citrus latifolia Tanaka). Periódico Tchê Química 2018, 15, 428-437. [CrossRef]

32. Adham, A.N. Comparative antimicrobrial activity of peel and juice extract of citrus fruits growing in Kurdistan/Iraq. Am. J. Microbiol. Res. 2015, 5, 155-159.

33. Tran, T.; Ngo, T.; Tran, T.; Bach, L.; Tran, T.; Huynh, X. Comparison of volatile compounds and antibacterial activity of Citrus aurantifolia, Citrus latifolia, and Citrus hystrix shell essential oils by pilot extraction. IOP Conf. Ser. Mater. Sci. Eng. 2021, 1092, 012076. [CrossRef]

34. Guimarães, A.C.; Meireles, L.M.; Lemos, M.F.; Guimarães, M.C.C.; Endringer, D.C.; Fronza, M.; Scherer, R. Antibacterial activity of terpenes and terpenoids present in essential oils. Molecules 2019, 24, 2471. [CrossRef] [PubMed] 
35. Guo, Q.; Liu, K.; Deng, W.; Zhong, B.; Yang, W.; Chun, J. Chemical composition and antimicrobial activity of Gannan navel orange (Citrus sinensis Osbeck cv. Newhall) peel essential oils. Food Sci. Nutr. 2018, 6, 1431-1437. [CrossRef] [PubMed]

36. Wishart, D.S.; Knox, C.; Guo, A.C.; Cheng, D.; Shrivastava, S.; Tzur, D.; Gautam, B.; Hassanali, M. DrugBank: A knowledgebase for drugs, drug actions and drug targets. Nucleic Acids Res. 2008, 36, D901-D906. [CrossRef] [PubMed]

37. CLSI. Performances for Antimicrobial Susceptibility Testing, 27th ed.; CLSI: Wayne, PA, USA, 2017; pp. 34, 36, 38. 